Artigo

\title{
O Nacional Desenvolvimentismo e as Políticas Públicas de Exercícios Físicos, Esporte e Lazer
}
The Developmentalism National and Public Policies of Physical Exercise, Sport and Leisure

El Nacional Desarrollismo y Políticas Públicas de Ejercicio Físico, Deporte y Ocio

Marco Antonio Bettine de Almeida ${ }^{1}$, Eduardo Mosna Xavier ${ }^{2}$ e Renata Ferreira dos Santos ${ }^{3}$

\footnotetext{
${ }^{1}$ Filiação institucional. Bacharel em Educação Física, mestre e doutor em Sociologia do Lazer pela Universidade Estadual de Campinas. Atualmente é docente do curso de Educação Física e Saúde e do Programa de Pós-Graduação Mudança Social e Participação Política da Escola de Artes Ciências e Humanidades da Universidade de São Paulo, São Paulo, SP, Brasiil.

Correspondência:

E-mail: marcobettine@gmail.com

${ }^{2}$ Filiação institucional. Bacharel em Ciências da Atividade Física e mestre em ciências pelo Programa de Pós-Graduação Mudança Social e Participação Política da Universidade de São Paulo, São Paulo, SP, Brasiil.

Correspondência: $\quad$ E-mail: eduardo.xavier@usp.br

${ }^{3}$ Filiação institucional. Bacharel em Ciências da Atividade Fisíca pela Universidade de São Paulo e mestre e doutoranda em Educação Física pela Universidade Estadual de Campinas, Campinas, SP, Brasil.

Correspondência: E-mail: renata.ferreira.santos@usp.br
} 
Resumo

Abstract

Resumen
O Período Nacional Desenvolvimentista Brasileiro (1946 a 1964) foi marcado pelo pujante crescimento industrial, além de uma sensível inversão populacional do eixo rural para o urbano. Essas transformações mobilizaram o governo a instituir políticas públicas que possibilitassem uma administração desse novo cenário. Nesse contexto, a atividade física (apesar da inexistência de uma pasta gerencial específica) também foi contemplada com algumas medidas que destacaram esse período do Estado Novo, e projetaram a compreensão e a realização do movimento humano para o esporte e a saúde, durante o Regime Militar. Assim, o Nacional Desenvolvimentismo foi um período marcante para a concretização de desejos do Estado, no tocante ao uso da atividade física como um instrumento de política pública, gerando reflexos que persistem na contemporaneidade.

Palavras-chave: Políticas Públicas, Atividade Física, Serviços Sociais, Educação Física Escolar, Esporte de Rendimento.

The National Developmental Period Brazilian (1946 to 1964) was marked by vigorous industrial growth, and a significant population inversion axis rural to urban. These transformations mobilized the government to institute policies that would enable the administration of this new scenario. In this context, physical activity (despite the absence of a specific folder management) was also considered with some measures that highlighted this period of the Estado Novo and designed the understanding and realization of human movement for sport and health during the military regime. Thus, the National Developmentalism was a remarkable period for the implementation of the State wishes regarding the use of physical activity as an instrument of public policy, creating repercussions that persist in contemporary times.

Keywords: Public Policy, Physical Activity, Social Services, Physical Education, Sports Performance.

El Nacional de Desarrollo Período Brasileiro (1946-1964) se caracterizó por el crecimiento industrial vigoroso, y un eje inversión de población sensible de las zonas rurales a las urbanas. Estas transformaciones se movilizaron al gobierno a establecer políticas que permitan a la administración de este nuevo escenario. En este contexto, la actividad física (a pesar de la ausencia de una gestión específica de la carpeta) también se consideró con algunas medidas que destacaron el período del Nuevo Estado, y diseñaron el entendimiento y la comprensión del movimiento humano para el deporte y la salud, durante el Régimen Militar. Así, el desarrollismo nacional fue un período extraordinario para la ejecución de los deseos del Estado, en relación con el uso de la actividad física como un instrumento de política pública, la creación de reflejos que persisten en la época contemporánea.

Palabras Clave: políticas públicas, Actividad Física, Servicios Sociales, Educación Física, Rendimiento Deportivo. 


\section{Análise Histórica do Nacional Desenvolvimentismo}

O expressivo crescimento econômico e industrial do Brasil Nacional Desenvolvimentista intensificou a migração do eixo rural para o urbano, potencializando essa transição populacional iniciada no Estado Novo. Para Braga (2006), esse período foi o que apresentou os maiores índices de movimentação populacional do eixo rural para o urbano:

Durante a década de 1950 registram-se as maiores taxas de migração interna da história do país, de acordo com os mesmos movimentos que se desenhavam nas décadas anteriores: Rio e São Paulo figuravam como os dois maiores centros de atração dos migrantes originários, principalmente, dos Estados do Nordeste e Leste (p. 2).

Ribeiro de Oliveira (2006) atrelou a migração do campo para as cidades em virtude do crescente processo de industrialização, peculiar ao Nacional Desenvolvimentismo, que gerou uma incipiente necessidade de mão de obra:

A fase que vai dos anos 50 aos 70 levou a marca do desenvolvimentismo na economia brasileira, foi um período de industrialização pesada, baseada no modelo de produção fordista. Isto demandava um expressivo contingente de mão-de-obra, o que impulsionou ainda mais as migrações internas, que já eram os deslocamentos de população predominantes nas duas décadas anteriores, intensificando ainda mais o processo de urbanização no país (p.7).

A inversão do eixo urbano e rural ocorreu concomitantemente com um perceptível crescimento demográfico no território nacional, impulsionado pelo aumento da natalidade e da expectativa de vida. Segundo o Instituto Brasileiro de Geografia e Estatística (IBGE), a população brasileira duplicou entre 1900 e 1940. As profissões de transformação, circulação e produção (típicas do cenário urbano) foram aquelas que apresentaram o maior crescimento naquele período.

Dados históricos sinalizam que a população brasileira apresentou um crescimento exponencial a partir de $1872^{1}$. A incipiente industrialização e comercialização de produtos refletiram numa maior intensidade de crescimento das cidades em relação às zonas rurais. Essa inversão "demográfica" ratificou a assunção de uma ideologia política primária iniciada durante o primeiro governo

1 Segundo Ribeiro de Oliveira (2006, p. 45), o início do expansivo crescimento brasileiro, a partir da segunda metade do século XIX, ocorreu em virtude da imigração europeia e asiática ao território nacional, sobretudo, "pela chegada de centenas de navios, dos mais diversos portos do mundo, com uma população ávida por trabalho e encantada por novas oportunidades". 
estado-novista de Getúlio Vargas, que determinava a valorização dos fatores econômicos em detrimento às intervenções na área social. Para Braga (2006), o comportamento político do poder vigente, bem como a materialização deste domínio através de obras públicas grandiloquentes e do expressivo crescimento financeiro, constituíram marcas indeléveis dos planos de governo dos mandatários do Poder Executivo Federal durante 0 Nacional Desenvolvimentismo.

A interferência do governo na formação de uma ideologia coletiva vinculada à industrialização e ao crescimento econômico constituiu um dos fatores basilares no fomento de políticas públicas concebidas durante o Nacional Desenvolvimentismo brasileiro. Para Debrun (1983), a propagação de conceitos sobre os ideais desenvolvimentistas resultou na incorporação de valores pelo indivíduo e pela própria sociedade, através de suas Instituições. Assim, a economia assumiu um papel singular e destacado para todas as medidas de intervenção governamentais, transformando-se em verdadeira ideologia política, sinalizando um "processo de transformação da Economia de ideologia secundária para primária” (p. 37).

Além do predomínio da economia como principal intervenção do governo na elaboração de políticas públicas, esse período também retratou o auge das medidas políticas adotadas em consonância às características subjetivas do mandatário (clientelismo, coronelismo, populismo, messianismo), utilizando as ferramentas existentes na máquina estatal em prol de uma divulgação midiática fomentadora de seus ideais desenvolvimentistas (Ribeiro De Oliveira, 2006).

A construção de Brasília, e as medidas propagandistas resultantes da divulgação desta ação, sempre enfatizando a pujança econômica, são fatos históricos relevantes para a caracterização desse período, pois refutavam eventuais manifestações contrárias às classes dirigentes, como dos emergentes (e ainda tímidos) movimentos sociais da época, além dos barulhentos e promissores Sindicatos (Andrade, 2010). A oração "Brasília: a Nova Capital do Brasil. Alguns contra muitos a favor. Todos beneficiados!", ilustra esse ideal de marketing institucional, constituindo um notório indicativo do modelo de gestão pública entre 1946 e 1964.

As políticas públicas desenvolvimentistas, orquestradas por Getúlio Vargas em seu segundo mandato (de 1951 a 1955) e idealizadas por Juscelino Kubitschek (de 1956 a 1960), exemplificaram esse modelo de governo, onde a personalidade do mandatário possuía uma maior importância quando comparada ao seu conhecimento político e administrativo para o exercício dessas funções. Cremonese (2006) ponderou sobre a perpétua necessidade brasileira de procurar protagonistas políticos com perfil similar ao descrito anteriormente, desde o Estado Novo até os dias atuais. Esses políticos incrementariam medidas como o "populismo", bem como outras ações personalistas (e, até mesmo, "messiânicas"), com o propósito de resolver os principais problemas da nação, "dependemos sempre de um líder: já que somos incapazes de construir nossa 
grandeza, quem sabe se um novo Dom Sebastião não o pode fazer por nós" ( $p$. 47).

O efervescente incremento de políticas públicas na área econômica e industrial, potencializado pelos efeitos de divulgação midiática de cunho excessivamente nacionalista, polarizou as produções históricas para esses temas. Organizações como o Instituto Superior de Pesquisas Brasileiras (ISEB), além do já citado IBGE, massificaram estudos estatísticos passíveis de análise e interpretação. Entretanto, em virtude da natural aproximação deste período com a industrialização, a maioria das publicações apresentou temas relacionados com esta temática, sem relações multidisciplinares, sobretudo, com a área de atividade física.

Além da importância dada às políticas econômicas e industriais, e da perceptível inversão do eixo populacional dos campos para as cidades, outros fatos que envolviam tais diretrizes governamentais também foram perceptíveis no período. O aumento do número de industriários e de comerciantes, impulsionados tanto pela fabricação como pelo consumo de produtos processados e terceirizados, constituiu outro importante elemento ilustrativo evidenciado no Nacional Desenvolvimentismo. Santos (2009) esclarece que os fatores primários e secundários que envolveram o Nacional Desenvolvimentismo sempre focaram o projeto de industrialização que o caracterizou, permitindo um singular acúmulo de capital por esse setor de produção, que "viria a construir o projeto de nação brasileira por meio de uma modernização conservadora" (p. 1).

O processo de industrialização foi decisivo na formação de uma plataforma de ofertas de empregos peculiares, refletindo diretamente na própria mão de obra (sobretudo a não qualificada). Esse tipo de efeito foi denominado por Ansara (2010) como "fatalismo". Para a autora, a marginalização social existente nas camadas menos privilegiadas da população latino-americana originou-se a partir da concepção de políticas públicas fomentadas inicialmente na década de 1950, gerando uma percepção coletiva de "aceitação e conformismo" de quem não tem condições de ascensão social, incorporando-se a uma espécie de "cotidianidade ${ }^{2 "}$ perversa:

O fatalismo, portanto, é um esquema ideológico, que se origina nas estruturas sociopolíticas e se enraíza psiquicamente, garantindo desse modo a reprodução da dominação social e a manutenção da ordem estabelecida. É um valioso instrumento ideológico que favorece as classes dominantes, visto que induz à aceitação da realidade social, gera comportamentos dóceis e estimula a resignação diante das

2 Segundo Heller (1985), a "cotidianidade", além de definir a vida de todo o homem, é um fenômeno atuante, fruído, heterogêneo e mutável, inserido na sociedade desde seus primórdios. Além disto, é responsável pela manutenção do comportamento das pessoas nele inseridas. 
exigências da vida. A concepção fatalista transforma os acontecimentos sociais em fenômenos naturais cuja alteração é improvável (p. 97).

O "fatalismo", além de sensivelmente percebido pelas classes operárias e comerciárias, foi notório a toda população brasileira. Esses efeitos foram potencializados pela própria intervenção governamental, que caracterizou aquele período. O "enraizamento" da consciência desenvolvimentista marcou a "cotidianidade" desse período de forma direta e perene, resultando numa completa identificação dos governantes e de suas medidas (através das políticas públicas) com a população.

A alta rotatividade política do Período não refletiu numa mudança na concepção "fatalista" da população, tampouco interferiu na modificação de uma "cotidianidade" que marcou o Nacional Desenvolvimentismo. Apesar da intensa alternância na chefia do Poder Executivo Federal (nove mudanças presidenciais, num período de dezoito anos), tal situação não resultou numa transformação significativa do pensamento e da participação política.

As constantes modificações de presidentes não interferiram no processo "fatalista" e de "cotidianidade" existente no período. Essa alienação coletiva da consciência e dos deveres políticos foi classificada por Baquero (2001) como "tecnocracia", ratificando uma percepção generalizada sobre a impossibilidade de modificação dessas rotinas, em virtude da "ausência de uma cidadania organizada e eficaz na defesa de seus interesses, o que somou numa deficiente mediação entre Estado, Sociedade e Partidos" (p. 99).

\section{Um Diagnóstico da Atividade Física e do Lazer no Nacional}

\section{Desenvolvimentismo}

A perspectiva de "modus vivendi" da população brasileira (com um claro enfoque tecnocrata, fatalista e alienado) conduziu as pessoas a estabelecerem rotinas sintetizadas numa jornada de trabalho mais controlada e limitada: 8 horas por dia, e 40 horas semanais, permitindo momentos de folga não vivenciados antes do Estado Novo (Ferreira, 2001).

Apesar dessa "ociosidade" do trabalhador preocupar o Governo, as limitações de exercício de liberdade do direito do trabalhador, consubstanciadas pela Constituição Federal de 1937, permitiam que o Poder Constituído não fomentasse políticas públicas para o preenchimento do tempo livre durante a Era Varguista. Não eram estipuladas, como prioridades básicas, dois tipos de vivências necessárias à manutenção da saúde e qualidade de vida: o lazer e a 
atividade física. O artigo 126, do referido diploma legal, excluía a atividade física como um dever do Estado para com a educação e à família brasileira:

Art 128 - A arte, a ciência e o ensino são livres à inciativa individual e a de associação ou pessoas coletivas públicas ou privadas. É dever do estado contribuir, direta ou indiretamente, para o estímulo e desenvolvimento de umas e de outro, favorecendo ou fundando fundações artísticas, científicas e de ensino.

O preenchimento do tempo livre e dos momentos de ócio seguia as diretrizes estabelecidas no Estado Novo, qual seja, da oferta de opções com o propósito de controle das ações humanas no período não laboral ou estudantil (Ferreira, 2001). As cerimônias nacionalistas (como as comemorações patrióticas da independência e da proclamação da república) tinham como propósito uma formação de caráter ideológico, enraizando princípios nacionais desenvolvimentistas na própria cultura popular (Soares, 2007).

As práticas de lazer populares (como os jogos que pulsavam nos morros, as brincadeiras de rua urbana e os festejos rurais populares) representavam práticas coletivas de convívio, repletas de simbolismo social. Entretanto, Almeida (2006), enfatizou que muitas dessas manifestações de cultura popular (com o propósito de preencher esse tempo livre) eram, na verdade, uma tentativa de manutenção das tradições ruralistas, em meio a um incipiente cenário de urbanização no Brasil. A busca por parques e áreas verdes, que resgatassem este tipo de espaço rural era comum no Período Nacional Desenvolvimentista.

Os jogos e brincadeiras representam exemplos de ações humanas exteriorizadas pelo movimento. Essas atividades motoras, realizadas de forma intencional nas ações de esporte, lazer e recreação, constituem importantes ferramentas para propiciar não apenas a saúde física como, também, a "mental", já que os seus efeitos ultrapassam os aspectos fisiológicos. Em sociedades que iniciam ou desenvolvem o processo de industrialização (caso do Brasil no Nacional Desenvolvimentismo), a oferta de atividade física à população proletária pode ser considerada como uma política pública estratégica, pois evitaria a manifestação de doenças nos trabalhadores, resultando numa maior produtividade laboral, como manifestado por estudiosos da época (Peregrino Júnior, 1949).

A associação da atividade física com o trabalho é fruto de pesquisas científicas atuais. Apesar da atual valorização do movimento físico, as políticas públicas do Nacional Desenvolvimentismo não vislumbravam essas ações humanas com a mesma intencionalidade. Além do esporte e da recreação não serem medidas prioritárias para o governo, o lazer carecia de uma maior prioridade de intervenção para o estabelecimento de políticas públicas (Soares, 2007). Almeida (2008), com embasamento em Habermas, pontuou que o lúdico suplantaria as expectativas subjetivas e individuais, resultando num apelo social diferenciado, pois permitiria uma melhor interação e convivência entre as 
pessoas dentro do chamado "Mundo da Vida" (local onde se estabelecem as relações humanas mais importantes, insusceptíveis de influência do poder e do dinheiro):

O lazer seria essencialmente uma relação social que se expressaria no Mundo da Vida. Ele seria uma prática intersubjetiva que foi definida no Mundo da Vida, não como parte de algum contexto particular, como família, parentesco ou norma, mas algo único que se interconecta com os diversos elementos do Mundo da Vida. O lazer ancora-se no Mundo da Vida e se expressa por ele. Como ocorre com o mundo vivido, o lazer também se complexifica, a partir da racionalização das formas de vida, criando novas maneiras de se relacionar com a sociedade (p. 35).

Nesse contexto, além de imprescindível para a manutenção das relações humanas, a incorporação de hábitos de vida saudáveis torna-se um importante elemento para a garantia de uma melhor saúde e qualidade de vida. Apesar destes reflexos da prática de esporte e exercícios não serem totalmente compreendidos naquele momento da história do Brasil, políticas públicas articuladas neste contexto poderiam refletir em formas concretas de inserção socioeconômica da população recém ingressa no cenário urbano. Desta forma, os fatores que explicam o perfil epidemiológico de um povo determinam não apenas as condições gerais de saúde como, também, caracterizam seu próprio estilo de vida.

Para que as políticas públicas articuladas nesse sentido atinjam o estilo de vida da população, é necessário que as pessoas incorporem as práticas físicas e lúdicas em seu cotidiano, através da conscientização social sobre a sua importância. Esse processo de internalização de elementos, segundo Ansara (2010), envolve diversas esferas de convivência (relacional, social, comunitário e político), estando "diretamente vinculada à relação com os sujeitos sociais, à ação coletiva e à transformação da sociedade" (p. 98).

O Nacional Desenvolvimentismo marcou não apenas a continuidade, mas também o apogeu das escolas higienistas ${ }^{3}$, oriundas no século XIX. Esta doutrina de concepção e propagação de exercícios e esporte (notadamente exteriorizada como uma política pública de intervenção neste cenário) priorizava a repetição de movimentos, almejando um corpo considerado "saudável". O treinamento físico e a ginástica eram amplamente disseminados, sobretudo, em clubes poliesportivos e em aulas escolares, na disciplina de educação física. Ademais, a década de 1940 marcou o ápice da Escola Francesa de prática de exercícios, uma

\footnotetext{
${ }^{3}$ A relação dos higienistas com a educação física possui uma história que extrapola as fronteiras brasileiras. Na verdade vários países da Europa, como Alemanha, Suécia, Dinamarca, dentre outros, tiveram sua história influenciada pela mentalidade da educação física, que por sua vez, foi influenciada pelos ideais higienistas (Goellner, 1992).
} 
das correntes com maiores características higienistas entre as existentes naquele período:

O aumento do rendimento atlético-esportivo após o Estado Novo, com o registro inicial de recordes, é alcançado com uma intervenção científico-racional sobre o corpo. Assim, os crescentes estudos na área esportiva e a valorização dos atletas eram medidas que retroalimentavam as próprias filosofias higienistas, propagando uma embrionária "política de valorização do corpo". Nesse cenário, a ginástica tornou-se uma "parte importante do movimento médicosocial do higienismo" (Bracht, 1999:74).

Além da disseminação do esporte, a doutrina higienista materializou o já tradicional apreço do povo pela prática de jogos físicos, sobretudo, aqueles que envolviam a participação coletiva (como o futebol, principal modalidade esportiva daquele período, persistindo até os dias atuais com a classificação de "esporte nacional"), como apontou Costa (2004):

O esporte (...) constitui um bem para o Brasil. E assim acontece porque expressa a identidade polissêmica, multicultural e miscigenada de seu povo. Além disso, o esporte historicamente em meio à diversidade nacional, sobrevive por ser comunitário em sua essência e por ter como base o voluntariado e, por vezes, a excelência entendida por boas práticas. Como tal, o esporte brasileiro possui valores intrínsecos e distintos das instituições do país e de seu governo ao ser observado como manifestação cultural, social, comunitária e até mesmo econômica (p. 7).

A educação física escolar também mereceu uma atenção diferenciada de intervenção. As aulas desta disciplina eram pedagogicamente elaboradas com exercícios calistênicos e de repetição, com forte teor militarista, típicos das doutrinas higienistas.

Dentre as escolas existentes, predominava no início do Nacional Desenvolvimentismo o "Sistema Francês". Essa doutrina se instaurou no Brasil durante o século XIX. Entretanto, apenas em meados do século XX, essa sistemática atingiu seu apogeu, em virtude de constituir-se como a principal orientação didática para a disciplina de educação física escolar, matéria obrigatória nas escolas e colégios públicos. Castro (1997) avaliou a evolução do método francês durante o Estado Novo, contextualizando quantitativamente sua hegemonia:

A rigorosa fiscalização pela Divisão de Educação Física levou o Método Francês a ser, em pouco tempo, efetivamente adotado em todos os cursos do Brasil: em 1938, 61,6\% dos estabelecimentos de ensino adotavam o Método Francês; em 1939, essa porcentagem subiu para 
81,3\%; em 1940, a 90,6\% e, em 1941, sua adoção foi praticamente integral (p. 11).

De natureza higienista, as aulas de educação física escolar também estimulavam o nacionalismo, notadamente durante o Estado Novo e o período estudado. Goellner (1992) acreditava que a escola seria o local propício para o alcance do "engrandecimento da Pátria" nesse período, já que poderia gerar a "formação de uma mão de obra produtiva, capaz de suprir e sustentar a industrialização emergente" (p. 155).

Além de uma formação de caráter nacionalista, as aulas de educação física escolar adotavam critérios pedagógicos que evidenciaram um embrionário processo de sistematização desta disciplina (Saviani, 1973). Essa política pública constituiu, apenas, uma faceta em relação às diversas medidas relativas à padronização e sistematização das grades curriculares nas escolas de ensino fundamental, médio e superior, em virtude da incisiva intervenção do Instituto Nacional de Ensino e Pesquisa (INEP), durante o Nacional Desenvolvimentismo (Skidmore, 1975).

O INEP (chefiado pelo Professor Anísio Teixeira ${ }^{4}$ entre 1952 e 1964) materializou na educação os objetivos governamentais existentes na classe política dirigente do período (Santos, 2009). Este Instituto programava intervenções educacionais sistemáticas, em consonância com os propósitos de "reconstrução nacional" (pautada na aceleração do crescimento econômico e social). A educação brasileira, de forma geral, experimentou na década de 1950 uma profunda cisão de estereótipos seculares, possibilitando a criação de disciplinas e especializações inovadoras, formando professores didaticamente diferenciados, além de permitir uma desburocratização de processos. Dessa forma, a modernização de conteúdo e de tecnologia da educação tornou-se mais célere, ocasionando uma verdadeira ampliação e melhoria na qualidade do ensino (Paiva; Paixão, 2002).

No contraponto da educação física escolar (com características higienistas e alto teor militarizado), o lazer no Brasil foi alvo de uma abordagem diferente durante o Nacional Desenvolvimentismo. As atividades lúdicas ofertavam alternativas para que o trabalhador pudesse manifestar-se, através de atos miméticos e catárticos, eventuais descontentamentos, extravasando "tensões agradáveis" (Elias, 1994, p. 20), gerando um sentimento de satisfação pessoal. Essa rotina era imprescindível dentro do chamado "Processo

4 Nos anos 1950, dirigiu o Instituto Nacional de Estudos Pedagógicos (INEP), órgão do Governo Federal que, no governo de Fernando Henrique Cardoso, passou a se chamar Instituto Nacional de Estudos e Pesquisas Educacionais Anísio Teixeira. Foi também o criador e primeiro dirigente da Campanha Nacional de Aperfeiçoamento de Pessoal de Nível Superior (CAPES), criada em 11 de julho de 1951, pelo Decreto no 29.741, pelo presidente Getúlio Vargas, e que Anísio dirigiu até a instituição da ditadura Militar, em 1964. 
Civilizador" ${ }^{5}$, garantindo uma continuidade social, através de uma ação reiterada, reproduzível no tempo e no espaço, extremamente necessária para uma vida em sociedade, onde “cada pessoa singular está realmente presa a ela" (Elias, 1994, p. 21).

Nesse contexto, o lazer ocuparia o "tempo livre" do trabalhador, sedimentando as relações sociais estabelecidas neste cenário. As atividades físicas e lúdicas realizadas nos momentos de folga evitam a ociosidade, permitindo o desenvolvimento de ações controladas pelo próprio Poder Público, que passa a exercer um importante mecanismo de monitoramento popular. Esse controle ocorre, segundo Gillet (2007), em virtude da multiplicidade de aspectos que resultam da prática de atividades lúdicas, suplantando o aspecto físico cultural:

O lazer é um tempo liberado, de acesso privilegiado à cultura e à educação, entre os tempos sociais constrangidos e os tempos sociais engajados, uma atividade entre produção e obrigações sociais. É o lugar onde se podem elaborar valores novos, um questionamento das regras habituais endossadas pelo trabalho, pela escola ou pela família, pela igreja ou partido. É também um espaço de conflito de valores (entre individualismo e engajamento coletivo, o trabalho por esforço ou por prazer), caracterizado por quatro propriedades: liberação, desinteresse, hedonismo e individualização, e três funções: descontração, divertimento e desenvolvimento (p. 33).

A presença do Estado na administração das atividades de lazer poderia inibir o desenvolvimento de todos os valores possíveis num cenário lúdico, como o próprio questionamento político e valorativo. O Nacional Desenvolvimentismo marcou o início da participação de agentes públicos na oferta de atividades de lazer, gerando reflexos nas futuras gerações, tanto nos tipos de atividades lúdicas a serem realizadas no tempo livre, como também na própria concepção subjetiva do significado do lazer (Santin, 1994).

\section{A legislação da Educação Física e Lazer no Nacional}

\section{Desenvolvimentismo}

5 Segundo Elias (1994), o “Processo Civilizador" é um mecanismo com raízes históricas profundas que busca amoldar as ações dos sujeitos a fim de tornar a convivência coletiva mais suportável. Viver em sociedade é altamente complexo e difícil. 
Apesar da evidente finalidade ideológica na elaboração de políticas públicas, bem como do natural e crescente interesse que o brasileiro manifestava pelo esporte e pelo lazer; a garantia e o respaldo para essas práticas ainda não haviam sido contempladas na legislação de maior referência durante o Nacional Desenvolvimentismo. A Constituição da República Federativa do Brasil, publicada em 18 de Setembro de 1946, não contemplava o direito às práticas de esporte e lazer em seu artigo 159, que preconizava os direitos individuais do cidadão brasileiro.

O forte apelo ideológico e de formação da consciência política, que pode ocorrer através da prática de atividade física, entretanto, não foi suficiente para que o governo ofertasse uma gestão administrativa elaborada nessa área. A constante mudança de pastas ministeriais responsáveis pelo gerenciamento de assuntos destinados ao esporte e à educação física escolar evidencia esse fato.

Esta dificuldade em encontrar um órgão gestor competente para administrar e promover o esporte e o lazer no Brasil, durante o Nacional Desenvolvimentismo, resultou num pequeno fomento de políticas públicas destinadas à essas áreas. O esporte competitivo, sobretudo o coletivo, constituía uma exceção ao cenário, já que a visibilidade olímpica positiva poderia alterar a percepção externa do país, favorecendo o seu estreitamento com as outras nações no próprio relacionamento econômico, motor propulsor desse período.

A primeira norma editada no Brasil com o intuito de regulamentar as práticas físicas e esportivas foi o Decreto Lei no 3.199, de 14 de abril de 1941, que criou o Conselho Nacional de Desportos (CND). Este aparelho administrativo, vinculado ao Ministério da Educação, priorizava a educação física escolar como principal medida fomentadora para as práticas desportivas no Brasil. O embrião deste Conselho foi concebido por teorias higienistas, que utilizavam esta disciplina como um instrumento para a formação de futuros cidadãos (Bracht, 1999). Além do caráter de conscientização política, o poder carismático exercido por Getúlio Vargas (Ferreira, 2001) funcionaria como um reforço positivo para potencializar este efeito sobre a referida disciplina.

Além da criação da referida disciplina como matéria curricular obrigatória, outras medidas públicas antecedentes foram tomadas para potencializar seus efeitos. Na Portaria $n^{\circ} 7$, de 9 de janeiro de 1940, o Diretor do Departamento Nacional de Educação, aprovou instruções para a realização de exames práticos de educação física nos estabelecimentos de ensino secundário. Já a Portaria Ministerial no 14, de 26 de janeiro de 1940, estabeleceu a exigência mínima de 3/4 de frequência dos alunos nas aulas de educação física para poderem se submeter aos exames finais das outras disciplinas da grade curricular.

Outra medida importante realizada neste período foi a determinação legal para que técnicos esportivos amadores fossem habilitados 
para os exercícios de suas funções. O Decreto-Lei no 2.975, de 23 janeiro de 1941, além de regulamentar o nivelamento técnico destes profissionais, determinou que as instituições desportivas seriam obrigadas a contratar pessoal legalmente habilitado em educação física para esta função (profissional com formação em nível superior ou com a habilitação de técnico desportivo em determinada modalidade).

O final do Estado Novo constituiu o marco inicial da participação da Administração Pública no controle (de forma direta e/ou indireta) e no fomento de políticas de intervenção no esporte brasileiro, tanto nos amadores como nos profissionalizados. O Decreto-Lei $n^{\circ}$ 8.458, de 26 de dezembro de 1945, dispunha sobre o registro dos estatutos das sociedades esportivas, bem como a necessidade do governo ter ciência de todas as medidas tomadas por essas instituições.

O período anterior ao Nacional Desenvolvimentismo também marcou a criação e a regulamentação de diversos cursos de graduação em educação física, indicando uma embrionária mudança paradigmática relacionada à qualificação técnica desses educadores, ensejando um maior conhecimento técnico científico para o exercício de suas funções, seja no esporte, na educação física escolar e, também, no lazer. Na década de 1940 foram criados os cursos superiores de educação física nas Universidades do Rio Grande do Sul (Decreto n 7.219, de 27 de maio de 1941), Piauí (Decreto $n^{\circ}$ 7.365, de 10 de junho de 1941), Santa Catarina (Decreto $n^{\circ}$ 7.366, de 10 de junho de 1941), Espírito Santo (Decreto-Lei no 3.384, de 3 de julho de 1941), Rio de Janeiro (Escola Nacional de Educação Física / Decreto-Lei no 4.029, de 19 de janeiro de 1942), Pernambuco (Decreto $\mathrm{n}^{\circ}$ 8.919, de 4 de março de 1942), Pará (Decreto $n^{\circ}$ 9.890, de 7 de julho de 1942), Rio Grande do Sul (Decreto $\mathrm{n}^{\circ}$ 15.582, de 16 de junho de 1944), Bauru/SP (Decreto no 47.174, de 6 de novembro de 1959).

A multiplicação e polarização dos cursos superiores, em contrapartida, gerou uma preocupação: organizar e sistematizar as modalidades esportivas praticadas por esses universitários durante a realização de sua graduação. Para preencher esta lacuna, foi editado o Decreto-Lei no 3.617, de 15 de setembro de 1941, que estabeleceu as bases de organização dos desportos universitários. Desta forma, foi instituída a Confederação Brasileira dos Desportos Universitários (CBDU), que regulamentou oficialmente a realização dos Jogos Universitários Brasileiros (JUB), comumentemente praticados desde o final do século XIX (com participação exclusiva de algumas entidades localizadas no eixo Rio de Janeiro São Paulo).

A regulamentação dos cursos na área de educação física também permitiu a maximização e disseminação de simpósios e congressos envolvendo a temática do esporte e do lazer, com enfoque na educação física escolar e no esporte. A Portaria Ministerial $n^{\circ}$ 310, de 16 de abril de 1942, aprovou o regimento do I Congresso Pan Americano de Educação Física, realizado na Escola Nacional de Educação Física, no Rio de Janeiro. 
A medida legal de maior importância no período histórico que antecedeu o Nacional Desenvolvimentismo foi aquela que criou o Conselho Nacional do Desporto (CND). O Decreto Lei no 3.199, de 14 de abril de 1941, foi o primeiro arcabouço legal que vislumbrou a necessidade de se observar as modalidades desportivas com um olhar mais profundo e complexo. Os objetivos propostos nesta legislação possuíam um forte ensejo ideológico, reconhecendo a necessidade preemente de profissionalização do esporte, sem desmerecer os benefícios de sua prática amadorística, como aponta o artigo 3ำ, alíneas a e b:

Art. 3으 - Compete precipuamente ao Conselho Nacional de Desportos:a) estudar e promover medidas que tenham por objetivo assegurar uma conveniente e constante disciplina à organização e à administração das associações e demais entidades desportivas do país, bem como tornar os desportos, cada vez mais, um eficiente processo de educação física e espiritual da juventude e uma alta expressão da cultura e da energia nacionais; b) incentivar, por todos os meios, o desenvolvimento do amadorismo, como prática de desportos educativa por excelência, e ao mesmo tempo exercer rigorosa vigilância sobre o profissionalismo, com o objetivo de mantê-lo dentro de princípios de estrita moralidade.

A letra legal que institui o CND evidenciou o teor nacionalista e moralista que permeava os objetivos de sua criação. O caráter ideológico das ações daquela instituição ensejava a formação sociocultural e política da população, exteriorizando uma estratégia de gestão que se iniciou no Estado Novo e se consolidou no Nacional Desenvolvimentismo, reconhecimento dos benefícios do esporte amador e a premente necessidade da profissionalização esportiva.

A transformação dos clubes poliesportivos em empresas foi outra característica marcante para o esporte nacional. Com a criação do CND, toda e qualquer entidade desportiva passou a ter uma responsabilidade administrativa em gerir com eficiência seus gastos e atividades, funcionalidade comum no competitivo setor privado. O Decreto-Lei $n^{\circ}$ 7.674, de 25 de setembro de 1945, determinou que todas as entidades desportivas públicas (como, por exemplo, as Confederações subordinadas ao CND) prestassem contas sobre a forma de utilização de seu capital financeiro, bem como estabeleceu medidas para a proteção do patrimônio dessas instituições.

A fiscalização das entidades desportivas foi facilitada pela regionalização do Conselho através das "Inspetorias Seccionais de Educação Física" (Decreto no 49.639, de 30 de dezembro de 1960). Com esta divisão de responsabilidades, tanto o esporte como a educação física escolar passa a ser observados pelo Governo Federal com maior proximidade, vislumbrando o futuro fomento de políticas públicas nesta área (Wacker, 2009). 
A educação física escolar recebeu distinta importância durante o Estado Novo. Além de Getúlio Vargas ratificar a obrigatoriedade desta disciplina, o número de aulas também aumentou durante a semana letiva. A Portaria Ministerial $n^{\circ}$ 167, de 8 de março de 1942, estabeleceu o mínimo de 2 sessões de exercícios físicos por semana na referida disciplina, ratificando não apenas sua obrigatoriedade, mas, também, uma frequencia curricular que refletia sua importância num contexto de políticas públicas articuladas na área da educação (Soares, 2007).

A valorização da disciplina de educação física foi materializada com a edição da Portaria Ministerial no 5, de 2 de janeiro de 1946, que tornou obrigatória as aulas de educação física, também, no Ensino Médio, fixando-as, no mínimo, em 2 sessões semanais de atividades dentro do currículo aplicado.

O ensino profissionalizante também foi contemplado com a obrigatoriedade da educação física escolar. Como o crescimento econômico era prioritário para os governantes, o esporte poderia contribuir não apenas para o condicionamento e a saúde, mas, também, para a própria formação moral desta futura mão de obra. Nesse esteio, o Decreto-Lei no 9.613, de 20 de agosto de 1946, também tornou obrigatória a educação física no ensino especializado agrícola.

As aulas de educação física escolar, no início do Nacional Desenvolvimentismo, mantinham-se fiéis ao método francês, visto que alinhava os benefícios higienistas com o condicionamento físico da futura mão de obra. $A$ utilização do professor para a execução e a posterior repetição dos movimentos pelos alunos, suplantava o caráter pedagógico dos exercícios, alcançando o campo paradigmático do modelo e referencial que o docente poderia fornecer ao discente. Nas palavras de Goellner (1992), esse processo já havia se iniciado, inclusive, antes do Estado Novo, com o uso das escolas como um instrumento de formação ideológica, de natureza nacionalista:

O despontar de um movimento de renovação educacional representou, nos anos 20, a tradução do pensamento desenvolvimentista aplicado à educação que, na perspectiva do engrandecimento da pátria, percebia na escola uma instância capaz de colaborar na concretização de tais fins, mediante sua reorganização. Percepção essa decorrente da necessária formação de mão de obra produtiva, capaz de suprir e sustentar a industrialização emergente (p. 32).

A educação, para o Estado Novo, simbolizava uma das medidas mais importantes para impulsionar o desenvolvimento da nação. Neste esteio, as escolas seriam espaços de alta significância para a formação deste cidadão, imbuído de um espírito patriótico e comprometido com os ditames emanados pelo poder constituído (Rodrigues, 2007). As aulas de educação física escolar 
representavam um microcosmo deste universo, onde se imergia o ensino básico e profissionalizante.

Com o surgimento dos estudos científicos que comprovaram os efeitos psicológicos gerados pela educação física escolar (Oliveira, 1979), os gestores públicos do Nacional Desenvolvimentismo passaram a idealizar políticas públicas que alcançassem os familiares destas crianças e adolescentes. O Decreto no 3.177, de 5 de fevereiro de 1958, instituiu a "Campanha Nacional de Educação Física", um programa do Governo Federal que visava o esclarecimento da sociedade acerca de todos os benefícios gerados pela prática de atividades físicas e de esporte pelas crianças e adolescentes. Além disto, proporcionava uma educação indireta dos genitores e familiares, com o objetivo de aproximálos desse estilo de vida, estimulando uma rotina mais saudável.

O Nacional Desenvolvimentismo também marcou a adoção da metodologia de "Ensino à Distância" para os cursos de educação física no Brasil. A Portaria no 6r, de 22 de janeiro de 1963, estabeleceu a criação do Curso Básico de Educação Física por Correspondência. Entretanto, apesar de contar com a fiscalização e com o acompanhamento do Ministério da Educação e Cultura (MEC), a referida graduação estava, efetivamente, "distante" e aquém dos conteúdos programáticos estipulados para a graduação presencial, gerando a extinção desta sistemática de ensino em 1969 (Grifi, 1989).

\section{O Nacional Desenvolvimentismo e as Políticas Públicas de Lazer}

O Nacional Desenvolvimentismo também marcou a utilização do lazer e da recreação como políticas públicas. Logo no início deste período, o Presidente Dutra emanou o Decreto-Lei $n^{\circ}$ 9.912, de 17 de setembro de 1946, determinando a construção das chamadas "praças de esportes". Estes espaços tinham como propósito a oferta de diversas modalidades esportivas. Como medida de reforço para a disponibilização de espaços que oferecessem aparelhos de esporte e lazer, a Lei $\mathrm{n}^{\circ}$ 4.240, de 28 de novembro de 1949, desapropriou locais abandonados para a construção das citadas praças. O pioneirismo na oferta destes locais, bem como o apelo popular causado pelos aparelhos disponíveis, resultaram numa contínua e perene utilização do conceito de "praças de esportes" nos governos que sucederam o General Dutra (Alves, 2003), sendo 
esse programa ofertado atualmente com o nome de "praças da juventude" ${ }^{6}$ pelo Governo Federal.

O esforço do Governo Federal na tentativa de utilizar o esporte nos espaços de recreação (frequentados, sobretudo, por crianças e adolescentes) era notório. Um exemplo desta preocupação existente no Nacional Desenvolvimentismo foi materializado na edição da Portaria no 101, de 22 de dezembro de 1958, que criou e patrocinou as chamadas "praias de recreio". Com atividades promovidas e coordenadas pela Divisão de Educação Física (DEF), do Ministério da Educação e Cultura (MEC), estes espaços ofertavam jogos e atividades físicas, sobretudo, para o público jovem. A maioria das atividades era realizada no mar, permitindo não apenas a prática de atividades físicas como, também, momentos de descontração e lazer para seus participantes. A maioria das atividades físicas realizadas ocorria dentro da água. Não ocorreu uma substantiva aderência ao programa em virtude de não se praticar esporte coletivo na areia. Entretanto, fica claro que a presença das famílias, com os seus filhos, insinuava uma influência indireta do público infanto-juvenil para que seus pais adotassem um estilo de vida mais saudável (Schneider; Neto, 2006).

A pujança econômica e o crescimento industrial brasileiro nortearam as principais políticas públicas existentes no território nacional que, impulsionadas por princípios oriundos da "tecnocracia", conduziram o Brasil para um processo "fatalista" de urbanização, sedimentando uma nova "cotidianidade" brasileira. Para subsidiar essa realidade, foi necessário manter o alto índice de migração do campo para as cidades (inversão populacional iniciada durante o Estado Novo). Esse processo deixou não apenas reflexos nos setores envolvidos, mas gerou uma sensível mudança no estilo de vida da população, que teve que se ambientar e estabelecer novas atividades de vida diária (Nahas, 2000), típicas dos centros urbanos.

Nesse contexto, a atividade física (embora não conhecida com essa terminologia naquele período) passou a ser um mecanismo de intervenção política, justificando sua incipiente valorização por parte dos governantes (aumento das legislações sobre as modalidades esportivas, criação do Conselho Nacional do Desporto, valorização curricular da disciplina de educação física escolar, entre outras). Tais políticas apresentaram adesão da população, justificada pelo crescimento da cultura do futebol no Brasil (Grifi, 1989).

6 Segundo o Ministério do Esporte, “o Projeto Praça da Juventude foi criado em 2007 com o objetivo de levar um equipamento esportivo público e qualificado para a população que pudesse, ao mesmo tempo, tornar-se ponto de referência para a juventude. É uma área de convivência comunitária onde são realizadas também atividades culturais, de inclusão digital e de lazer para a população de todas as faixas etárias". Informação disponível em <http//www.governofederal.org.br/lazer>. Acesso em 12 de fev. 2012. 
As políticas públicas de lazer também começaram a se multiplicar, sempre relacionadas com a prática de esporte e de exercícios em espaços públicos (como as "praias de recreio", as "praças de esportes" e as ações lúdicas e recreativas em parques públicos), sendo que muitas dessas medidas subsistem até a contemporaneidade. Essas intervenções permitiam a oferta de atividades para preencher o tempo livre da população recentemente urbanizada, fora do trabalho e das escolas, contribuindo para esse processo de adaptação durante o Nacional Desenvolvimentismo.

\section{Referencias Bibliográficas}

Almeida, Marco Antonio Bettine de. (2008). Análise do desenvolvimento das práticas urbanas de lazer relacionadas à produção cultural no período nacional-desenvolvimentista à globalização através da "Teoria da Ação Comunicativa". Tese (doutorado). Universidade Estadual de Campinas. Campinas.

Almeida, Marco Antonio Bettine de. (2006) Lazer no Estado Novo e os usos do tempo livre. Revista Lecturas: Educación física y deportes, n. 98.

Alves, Vânia de Noronha. (2003). Uma leitura antropológica sobre educação física e lazer. In: Lazer, recreação e educação física. Editora Autêntica: Belo Horizonte.

Andrade, Inácio Carvalho Dias de. (2010). Movimento social, cotidiano e política: uma etnografia da questão identitária dos sem teto. Dissertação (mestrado). Universidade de São Paulo. São Paulo.

Ansara, Soraia. (2010). Intervenções psicossociais na comunidade: desafios e práticas. Psicologia \& Sociedade, 22(1), 95-103. São Paulo.

Baquero, Marcello. (2001). Cultura política participativa e desconsolidação democrática. Revista São Paulo em Perspectiva, p. 98 - 104. São Paulo.

Bracht, Valter. (1999). A Constituição das teorias pedagógicas da educação física. Caderno CEDES, ano XIX, no 48, Agosto. São Paulo.

Braga, Fernando Gomes. (2006). Migração interna e urbanização no Brasil contemporâneo: Um estudo da rede de localidades centrais do Brasil (1980/2000). Trabalho apresentado no XV Encontro Nacional de Estudos Populacionais, ABEP, realizado em Caxambú - MG - Brasil, de 18 a 22 de setembro. 
Castro, Celso. (1997). Corpore Sano: Os militares e a introdução da educação física no Brasil. Revista Antropolítica, no 02. Rio de Janeiro.

Costa, Lamartine Pereira da et al. (2004). Atlas de educação física e esporte no Brasil. Editora CONFEF. São Paulo.

Cremonese, Djalma. (2006). Insolidarismo e cordialidade: uma análise das mazelas políticas no Brasil. In: Capital Social: Teoria e Prática. Editora UNIJIU: Porto Alegre.

Debrun, Michel. (1983). A conciliação e outras estratégias. Editora Brasiliense: São Paulo.

Elias, Norbert. (1994). O processo civilizador. Rio de Janeiro: Editora Jorge Zahar: Rio de Janeiro.

Ferreira, Jorge. (2001). O populismo e sua história. Editora Civilização Brasileira: Rio de Janeiro.

Gillet, Jean Claude. (2007). O sistema de animação sócio cultural francês: entre diversão e educação, a conquista permanente de uma viva democracia. In: Recreação, Esporte e Lazer. Editora Instituto Tempo Livre: Recife.

Goellner, Silvana Villodre. (1992). O método francês e a educação física no Brasil: da caserna à escola. Dissertação (mestrado). Universidade Federal do Rio Grande do Sul. Porto Alegre.

Grifi, Giampiero. (1989). História da educação física e do esporte. Editora Luzzatto: Porto Alegre.

Heller, Agnes. (1985). O cotidiano e a história. Editora Paz e Terra: São Paulo.

Nahas, Markus Vinicius. (2000). Atividade física, lazer e qualidade de vida. Editora EDUSP: São Paulo.

Oliveira, Vitor Marinho de. (1979). O que é educação física. 2a Edição. Editora Brasiliense: São Paulo.

Paiva, Edil Vasconcellos; Paixão, Léa Pinheiro. (2002). PABAEE (1956-1964): a americanização do ensino elementar? Editora EdUFF: Niterói.

Peregino Júnior, João da Rocha Fagundes. (1949). Sentidos e objetivos da educação física. In: Arquivos da Escola Nacional da Educação física e Desporto. Universidade do Brasil, ano V, no 5 . Rio de Janeiro.

Ribeiro De Oliveira, Antônio Tadeu. (2006). Dos movimentos populacionais à pendularidade: uma revisão do fenômeno migratório no Brasil. Trabalho apresentado no XV Encontro Nacional de Estudos Populacionais, ABEP, Caxambú-MG, de 18 a 22 de Setembro. 
Rodrigues, José. (2007). Formar homens que o Brasil necessita, eis a tarefa da educação: o pensamento pedagógico industrial na Era Vargas. Revista HISTEDBRR, no 26. Campinas.

Santin, Silvino. (1994). Educação física: da alegria do lúdico à opressão do rendimento. Edições ESEF: Porto Alegre.

Santos, Jane Maria. (2009). Ensino industrial no contexto do Nacional Desenvolvimento. Dissertação (mestrado). Universidade Federal de Uberlândia. Belo Horizonte.

Saviani, Demerval. (1973). Educação brasileira: estrutura e sistema. Editora Saraiva. São Paulo.

Schneider, Omar; Neto, Amarílio Ferreira. (2006). Saúde e escolarização representações, intelectuais, educação e educação física. In: Oliveira, M.A.T. Educação do corpo na escola brasileira. Editora Autores Associados: Campinas.

Soares, Carmem Lúcia. (2007). Educação física: raízes europeias e Brasil. Editora SP Associados: São Paulo.

Skidmore, Thomas. (1975). Brasil: de Getulio Vargas a Castelo Branco (19301964). Editora Paz e Terra: Rio de Janeiro.

Wacker, Márcia de Franceschi Neto. (2009). Educação olímpica, olimpismo e euritmia. In: Olimpismo e educação olímpica no Brasil. Editora UFRGS: Porto Alegre. 